\title{
Sensitivity and specificity of prenatal screening methods for detection of risk of fetal chromosomal abnormalities
}

\author{
Sunil Kumar Juneja, Pooja Tandon*, Anjali Sharma, Anshu Sharma
}

Department of Obstetrics and Gynecology, DMCH, Ludhiana, Punjab, India

Received: 28 June 2019

Revised: 27 December 2019

Accepted: 02 January 2020

\author{
*Correspondence: \\ Dr. Pooja Tandon, \\ E-mail: drpoojatandon77@gmail.com
}

Copyright: (C) the author(s), publisher and licensee Medip Academy. This is an open-access article distributed under the terms of the Creative Commons Attribution Non-Commercial License, which permits unrestricted non-commercial use, distribution, and reproduction in any medium, provided the original work is properly cited.

\begin{abstract}
Background: Babies born with chromosomal abnormalities pose a burden on the family as well as the society at large. Early detection and management of fetal chromosomal abnormalities has become an essential component of antenatal care. Hence pregnant women of all ages are offered screening methods for early detection of chromosomal abnormalities. We intended to study the sensitivity and specificity of prenatal screening methods for detection of risk of fetal chromosomal abnormalities.

Methods: A three-year retrospective study was conducted from January 2015 to December 2017 in 258 singleton pregnant mothers attending antenatal clinic and delivering at $\mathrm{DMCH}$. The patients were screened for chromosomal abnormalities in the first trimester by NB NT scan along with dual marker and level II anomaly screen scan along with quadruple test in the second trimester. Based on the test results the patients were classified into high risk and low risk pregnant mothers. All the patients with abnormal quadruple test were subjected to amniocentesis for karyotyping. The results of the first trimester and second trimester screening methods were statistically analyzed using chi square test, sensitivity and specificity of the prenatal screening methods was calculated.

Results: The sensitivity and specificity of dual marker test for detection of chromosomal abnormality is $50 \%$ and $85.94 \%$ respectively and that of quadruple test sensitivity is $50 \%$, specificity is $95.3 \%$. The difference was highly significant in the favour of the quadruple marker with P-value of 0.0004 .

Conclusions: While counseling the patients regarding possibility of having abnormal fetus, obstetrician should keep in mind the false negatives and false positives of prenatal screening and diagnostic methods.
\end{abstract}

Keywords: Fetal chromosomal abnormalities, First trimester screening, Second trimester screening, Sensitivity, Specificity

\section{INTRODUCTION}

Babies born with chromosomal abnormalities pose a burden on the family as well as the society at large. Early detection and management of fetal chromosomal abnormalities has become an essential component of antenatal care. Hence pregnant women of all ages are offered screening methods for early detection of chromosomal abnormalities. Commonly detected chromosomal abnormalities include Down's syndrome (trisomy 21), Patau syndrome (trisomy 13), Edward syndrome (trisomy 18), Turner syndrome (XO) etc. ${ }^{1}$ Various modalities used for detection of these include USG and biochemical markers. ${ }^{2}$ First Trimester Screening consists of ultrasonography done at 11-13 weeks 6 days of pregnancy for nuchal translucency and nasal bone and double marker that includes detection of pregnancy associated plasma protein A (PAPP-A) levels 
and free beta hcG levels. Second trimester screening includes anomaly screen level II scan and quadruple test (AFP, unconjugated estriol levels, hcG and inhibin A levels).

\section{METHODS}

A three-year retrospective study was conducted from January 2015 to December 2017 at Dayanand Medical College and Hospital, Ludhiana, a tertiary care centre.

\section{Inclusion criteria}

- Women with singleton pregnancy who underwent first and second trimester screening for detection of chromosomally abnormal fetus before twenty weeks of gestation.

\section{Exclusion criteria}

- Mutifetal pregnancy, pregnant women who refused testing and pregnant women who reported after twenty weeks of gestation.

There were 258 singleton pregnant mothers attending antenatal clinic at $\mathrm{DMCH}$, who were screened for chromosomal abnormalities in the first trimester by NB NT scan along with dual marker and level II anomaly screen scan along with quadruple test in the second trimester. Based on the test results the patients were classified into high risk and low risk pregnant mothers. All the patients with abnormal quadruple test were subjected to amniocentesis for karyotyping.

\section{Statistical analysis}

Data were described in terms of range; frequencies (number of cases) and relative frequencies (percentages) as appropriate. For comparing categorical data, Chi square $\left(\chi^{2}\right)$ test was performed and exact test was used when the expected frequency is less than 5. Sensitivity and specificity were also determined. A probability value (P-value) less than 0.05 was considered statistically significant. All statistical calculations were done using SPSS (statistical package for the social science) SPSS 17 version statistical program for Microsoft Windows.

\section{RESULTS}

A total $61.6 \%$ of patients belonged to the age group $<30$ years and $35.7 \%$ belonged to the age group of $31-40$ years (Table 1).

Table 1: Distribution of patients according to age.

\begin{tabular}{|lll|}
\hline Age group & No. of patients & $\%$ \\
\hline$<30$ & 159 & $61.6 \%$ \\
\hline $31-40$ & 92 & $35.7 \%$ \\
\hline$>40$ & 7 & $2.7 \%$ \\
\hline Total & $\mathbf{2 5 8}$ & $\mathbf{1 0 0 \%}$ \\
\hline
\end{tabular}

Table 2: Distribution of patients according to gravidity.

\begin{tabular}{|lll|}
\hline Gravida & No. of patients & $\%$ \\
\hline Multi & 139 & $53.9 \%$ \\
\hline Primi & 119 & $46.1 \%$ \\
\hline Total & $\mathbf{2 5 8}$ & $\mathbf{1 0 0 \%}$ \\
\hline
\end{tabular}

A total $53.9 \%$ of patients in the study were multigravida (Table 2). All 258 patients had normal NB/NT scan.

Table 3: Distribution of patients according to PAPP-A and beta-hcG.

\begin{tabular}{|lll|}
\hline PAPP A & No. of patients & $\%$ \\
\hline High risk & 37 & $14.3 \%$ \\
\hline Low risk & 221 & $85.6 \%$ \\
\hline Total & $\mathbf{2 5 8}$ & $\mathbf{1 0 0 \%}$ \\
\hline
\end{tabular}

Increased risk for fetal abnormalities in patients according to PAPP-A and beta-hcG was found in $14.3 \%$ patients $(\mathrm{N}=37)($ Table 3$)$.

Table 4: Distribution of patients according to quadruple marker (beta-hcG AFP, estriol, inhibin-A.

\begin{tabular}{|lll|}
\hline Quad test & No. of patients & $\%$ \\
\hline High risk & 13 & $5.03 \%$ \\
\hline Low risk & 245 & $94.96 \%$ \\
\hline Total & $\mathbf{2 5 8}$ & $\mathbf{1 0 0 \%}$ \\
\hline
\end{tabular}

A total $94.6 \%(\mathrm{~N}=245)$ patients had low risk result on quadruple marker test and rest $5.03 \%(\mathrm{n}=13)$ patients had high risk result on quadruple marker test (Table 4).

Table 5: Distribution of patients according to level II scan.

\begin{tabular}{|lll|}
\hline Level $2 /$ anomaly scan & No. of patients & $\%$ \\
\hline Normal & 258 & $100 \%$ \\
\hline
\end{tabular}

Table 6: Distribution of patients according to amniocentesis.

\begin{tabular}{|llll|}
\hline Amniocentesis & $\begin{array}{l}\text { No. of } \\
\text { patients }\end{array}$ & Result & $\%$ \\
\hline $\begin{array}{l}\text { Procedure done but no } \\
\text { abnormality }\end{array}$ & 13 & Normal & $5.03 \%$ \\
\hline Procedure not done & 245 & N/a & $94.96 \%$ \\
\hline Total & $\mathbf{2 5 8}$ & & $\mathbf{1 0 0 \%}$ \\
\hline
\end{tabular}

Table 7: distribution of patients according to mode of delivery.

\begin{tabular}{|lll|}
\hline LSCS/NVD & No. of patients & $\%$ \\
\hline LSCS & 98 & $37.9 \%$ \\
\hline NVD & 160 & $62.01 \%$ \\
\hline Total & $\mathbf{2 5 8}$ & $\mathbf{1 0 0 . 0 \%}$ \\
\hline
\end{tabular}


All 258 patients had normal level 2 scan (Table 5). In $5.03 \%(\mathrm{~N}=13)$ patients, amniocentesis was done but no abnormality was found (Table 6). A total $37.9 \%(\mathrm{~N}=98)$ patients were delivered by LSCS (Table 7).

In multigravida patients 52 delivered by LSCS and 87 delivered vaginally and in primigravida patients 46 delivered by a LSCS and 73 delivered vaginally (Table 8).

A total $2(0.8 \%)$ out of 258 patients gave birth to babies with Down's syndrome (Table 9).

Table 8: Distribution of patients according to mode of delivery and gravidity.

\begin{tabular}{|lllllll|}
\hline & & LSCS/NVD & & Total & Chi-square & P-value \\
\hline \multirow{2}{*}{ Gravida group } & Multi & 52 & NVD & 87 & 139 & \\
& PRIMI & 46 & 73 & 119 & 0.042 & 0.837 \\
\hline Total & & $\mathbf{9 8}$ & $\mathbf{1 6 0}$ & $\mathbf{2 5 8}$ & & \\
\hline
\end{tabular}

Table 9: Distribution of patients according to Down's syndrome.

\begin{tabular}{|lll|}
\hline Outcome & No. of patients & $\%$ \\
\hline baby with Down syndrome & 2 & $0.8 \%$ \\
\hline Normal & 256 & $99.2 \%$ \\
\hline Total & $\mathbf{2 5 8}$ & $\mathbf{1 0 0 . 0 \%}$ \\
\hline
\end{tabular}

The dual marker identified 37 out of 258 patients as high risk whereas quadruple marker identified 13 high risk patients, however in none of the 258 patients any anomaly was detected on ultrasonography. To further substantiate the pregnant mothers belonging to high risk group, 13 patients identified by quadruple marker test were subjected to amniocentesis and karyotyping. None of the 13 high risk patients had abnormal karyotyping. All the patients were followed up throughout the pregnancy with subsequent clinical monitoring and ultasonography and 256 pregnancies resulted in good fetal outcomes, however in the high risk group, in the screen positive, amniocentesis negative patient, after birth one new-born was found to be having Down's syndrome This patient was 36 years old and was a multigravida. One neonate in low risk group was also found to be suffering from down's syndrome and the patient was 30 years old primigravida.

Table 10: Specificity and sensitivity of dual marker.

\begin{tabular}{|llll|}
\hline Dual marker & No down syndrome & Down syndrome & Number of patients \\
\hline Screen positive & 36 (false positive) & 1 (True positive) & 37 \\
\hline Screen negative & 220 (true negative) & 1 (false negative) & 221 \\
\hline Total patients & $\mathbf{2 5 6}$ & $\mathbf{2}$ & $\mathbf{2 5 8}$ \\
\hline
\end{tabular}

Sensitivity $=$ True positive $/$ true positive + false negative $=1 / 2=50 \%$, Specificity $=$ true negative/ false positive + true negative $=$ $220 / 256=85.94 \%$.

Table 11: Specificity and sensitivity of quadruple marker.

\begin{tabular}{|llll|}
\hline Quadruple test & No down syndrome & Down syndrome & Number of patients \\
\hline Screen positive & 12 (false positive) & 1 true positive) & 13 \\
\hline Screen negative & 244 (true negative) & 1 (false negative) & 245 \\
\hline Total patients & $\mathbf{2 5 6}$ & $\mathbf{2}$ & $\mathbf{2 5 8}$ \\
\hline
\end{tabular}

Sensitivity $=$ True positive $/$ True positive + False negative $=1 / 2=50 \%$, Specificity $=$ True negative $/$ False positive + True negative $=$ $244 / 256=95.3 \%$.

In our study in high risk dual marker or quadruple test patients, amniocentesis was done, no abnormality detected but one patient who was high risk for dual or quadruple test was found to have baby with Down's syndrome. On other hand, one patient who had low risk dual test and quadruple test, amniocentesis was not done and baby had Down's syndrome.
Using statistical analysis with chi square and $\mathrm{P}$-value, our study concludes for dual marker, sensitivity is $50 \%$ and $85.94 \%$ specificity (Table 10 ).

For quadruple test, sensitivity is $50 \%$ and $95.3 \%$ specificity. Our results are comparable with other national and international studies (Table 11). 
Study concludes that the sensitivity and specificity of dual marker test for detection of chromosomal abnormality is $50 \%$ and $85.94 \%$ respectively and that of quadruple test sensitivity is $50 \%$, specificity is $95.3 \%$. The difference was highly significant in the favour of the quadruple marker with P-value of 0.0004.

This study brings forth the inability of dual marker, quadruple marker, sonography, amniocentesis and karyotyping in identification of down's syndrome in study population.

\section{DISCUSSION}

Down syndrome (also known as trisomy 21) is the most common chromosomal abnormality detected with first trimester screening and is caused by the occurrence of an extra chromosome; chromosome 21 . This results in a range of physical features, health problems, developmental delay and some level of intellectual disability. ${ }^{1}$

Other chromosome abnormalities such as Edward syndrome (trisomy 18) and Patau syndrome (trisomy 13) occur less often than Down syndrome but have more severe effects on the baby. Chromosome abnormalities cannot be reversed once they occur. ${ }^{2}$

Down syndrome occurs in approximately one in 600 births. There are numerous methods for screening and diagnosis of Down syndrome during pregnancy. Nowadays, pregnant women are undergoing ultrasonography for evaluating the thickness of nuchal translucency and presence of nasal bone between 11 to 13.6 weeks of pregnancy. Nuchal Translucency is subcutaneous accumulation of fluid at the nape of neck measured in neutral position. Increased NT levels and absence of nasal bone are markers for Down's syndrome.

Considering crown rump length between 45-84 mm, NT level less than $3 \mathrm{~mm}$ is considered normal at 11 to 13 weeks 6 days. As the value of NT increases, risk of chromosomal abnormality increases. During the first trimester of pregnancy, blood tests are conducted to check the probability of Down's syndrome, but unfortunately, false positive results seem to be inevitable in blood tests. Therefore, in some cases further tests are required in order to become certain about the diagnosis. ${ }^{3,4}$ Nuchal translucency testing should be combined with serum measurements of pregnancy-associated plasma protein A (PAPP-A) and human chorionic gonadotropin (hcG) during the first trimester to improve the detection rate of Down syndrome to 78.7 to 89 percent, with a false-positive rate of 5 percent. ${ }^{5-8}$ Decreased levels of PAPP-A before the $14^{\text {th }}$ week of gestation are associated with an increased risk for Down syndrome and trisomy 18. Whereas increased levels of hcG are associated with an increased risk of Down syndrome. Low levels of PAPP A are associated with adverse pregnancy outcomes, such as spontaneous loss before fetal viability, gestational hypertension, preeclampsia, preterm premature rupture of membranes, placental abruption, preterm birth, low birth weight, and stillbirth. ${ }^{9,10}$

Quadruple test is performed between 16 to 20 weeks of pregnancy. This test includes estimation of following hormones alpha fetoprotein, beta hcG, unconjugated estriol and Inhibin A levels. ${ }^{11}$

If any of the screening method comes out to be positive, it indicates increased risk of chromosomal abnormalities, such patients can be offered procedures like amniocentesis which are more specific for making definitive diagnosis. Amniocentesis is a prenatal test done between 15-18 weeks of pregnancy in which a small amount of amniotic fluid is removed from the sac surrounding the fetus for testing. The sample of amniotic fluid is removed through a fine needle inserted into the uterus through the abdomen, under ultrasound guidance. The fluid is then sent to a laboratory for analysis. Different tests can be performed on a sample of amniotic fluid, depending on the genetic risk and indication for the test. An estimated risk is calculated and adjusted for the expectant mother's age; if she's diabetic; if she's having twins or other multiples, and the gestational age of the fetus. ${ }^{12}$ Weight and ethnicity also used in adjustments. ${ }^{13}$

Our study aimed at comparing sensitivity and specificity of first trimester and second trimester screening methods for early detection of fetal chromosomal abnormalities.

In various studies, following observations were made maternal age to provide an effective method of screening for trisomy 21; for an invasive testing rate of $5 \%$, about $75 \%$ of trisomic pregnancies can be identified. When maternal serum free B-human chorionic gonadotropin and pregnancy-associated plasma protein-A at $11(+0)$ 13 (+6) weeks are also taken into account, the detection rate of chromosomal defects is about $85-90 \%$. In $60-70 \%$ of fetuses with trisomy 21 the nasal bone is not visible at the $11(+0)-13(+6)$ weeks scan and examination of the nasal bone can increase the detection rate of screening by the first trimester scan and serum biochemistry to more than $95 \% .^{14}$

When nuchal translucency (NT) parameter is used alone for detecting Down syndrome, sensitivity is $62 \%$ and false positive rate is $5 \%$. If we combine NT with blood tests - beta hcG and PAPP-A, sensitivity improves to $73 \%$ and false positive rate is $4.7 \% .^{15}$

When NT used alone, detection rate for trisomy 21 was $88 \%$ and for trisomy 18 , detection rate was $75 \%$, when ultrasound feature of absent nasal bone was used detection rates increased up to $95 \%$ and more. ${ }^{15}$

Quadruple test has $81 \%$ sensitivity and 5\% false positive rate. $^{5}$ 
Amniocentesis has $99.4 \%$ detection rate of Down's syndrome with almost zero $\%$ false positive rate. The results of this study were were in contrast to our study. ${ }^{16}$

\section{CONCLUSION}

Inspite of the fact that amniocentesis has highest detection rate with zero false positive rate, first trimester screening methods and quadruple test should still be the primary modality i.e. with help of nuchal translucency, nasal bone and blood tests of beta hcG and PAPP A levels, early detection of various fetal chromosomal abnormalities is possible without subjecting patients to invasive procedures like amniocentesis.

Risk of having a Down's syndrome affected baby cannot be ruled out even after undergoing invasive testing amniocentesis Therefore while counselling the patients regarding possibility of having abnormal fetus, obstetrician should keep in mind the false negatives and false positives of prenatal screening and diagnostic methods.

Funding: No funding sources

Conflict of interest: None declared

Ethical approval: The study was approved by the Institutional Ethics Committee

\section{REFERENCES}

1. Anderson CL, Brown CEL. University of Texas Medical Branch, Austin, Texas - fetal chromosomal abnormalities: antenatal screening and diagnosis. Am Fam Physician. 2009;79(2):117-23.

2. Benn P, Chapman AR. Ethical and practical challenges in providing noninvasive prenatal testing for chromosome abnormalities: an update. Curr Opinion Obstet Gynecol. 2016;28(2):119-24.

3. Natoli JL, Ackerman DL, McDermott S, Edwards JG. Prenatal diagnosis of Down syndrome: a systematic review of termination rates. Prenat Diagn. 2012;32:14253.

4. Wapner R, Thom E, Simpson JL, Pergament E, Silver $\mathrm{R}$, Filkins $\mathrm{K}$, et al. First-trimester screening for trisomies 21 and 18. New Eng J Med. 2003;349(15):1405-13.

5. Nicolaides KH. Nuchal translucency and other firsttrimester sonographic markers of chromosomal abnormalities. Am J Obstet Gynecol. 2004;191(1):4567.

6. Malone FD, Berkowitz RL, Canick JA, D'Alton ME. First-trimester screening for aneuploidy: research or standard of care? Am J Obstet Gynecol. 2000;182(3):490-6.
7. Spencer K, Souter V, Tul N, Snijders R, Nicolaides KH. A screening program for trisomy 21 at 10-14 weeks using fetal nuchal translucency, maternal serum free beta-human chorionic gonadotropin and pregnancyassociated plasma protein-A. Ultrasound Obstet Gynecol. 1999;13(4):231-7.

8. Dugoff L, Hobbins JC, Malone FD, Porter TF, Luthy D, Comstock $\mathrm{CH}$, et al.0 First-trimester maternal serum PAPP-A and free-beta subunit human chorionic gonadotropin concentrations and nuchal translucency are associated with obstetric complications: a population-based screening study (the FASTER Trial). Am J Obstet Gynecol. 2004;191(4):1446-51.

9. Smith GC, Shah I, Crossley JA, Aitken DA, Pell JP, Nelson SM, et al. Pregnancy-associated plasma protein A and alpha-fetoprotein and prediction of adverse perinatal outcome. Obstet Gynecol. 2006;107(1):161-6.

10. Wald NJ, Morris JK, Ibison J, Wu T, George LM. Screening in early pregnancy pre-eclampsia using Down Syndrome quadruple test markers. Prenat. Diagn. 2006;26(6):559-64.

11. Chaudhury K, Mukherjee K. Sensitivity and Specificity of a prenatal screening method using the combination of maternal age and fetal nuchal translucency thickness for fetal aneuploidy: a clinical study in Eastern India. Int $\mathrm{J}$ Reprod Contracept Obstet Gynecol. 2016;5:148-53.

12. Nicolades KH. Turning the pyramid of prenatal care. Fetal Diagn Ther. 2011;29:183-96.

13. Sieroszewski P, Perenc M, Baś-Budecka. Ultrasound diagnostic schema for the determination of increased risk for chromosomal fetal aneuploidies in the first half of pregnancy. J Appl Genet. 2006;47(2):177-85.

14. Lao MR, Calhoun BC, Bracero LA, Wang Y, Seybold DJ, Broce M, et al. The ability of the quadruple test to predict adverse perinatal outcomes in a high-risk obstetric population. J Med Screen. 2009;16(2):55-9.

15. Akbari M, Mirmazloumi SH, Garshasbi M, Talari ZS, Sadeghi F. Specificity and Sensitivity of NIPT for Prenatal Screening of Down Syndrome in 100 Pregnant Women from Tonekabon, Iran. Med Clin Rev. 2018;4(1):3.

16. Shohat M, Akstein E, Davidov B, Barkai G, Legum C, David M. Amniocentesis rate and the detection of down syndrome and other chromosomal anomalies in Israel. Prenatal Diagnos. 1995;15(10):967-70.

Cite this article as: Juneja SK, Tandon P, Sharma A Sharma A. Sensitivity and specificity of prenatal screening methods for detection of risk of fetal chromosomal abnormalities. Int J Reprod Contracept Obstet Gynecol 2020;9:540-4. 